@ERSpublications

Adolescent FEV1 decline in cystic fibrosis may be an artefact of the spirometry reference equations used http://ow.ly/J0com

Sanja Stanojevic ${ }^{1}$, Diana Bilton ${ }^{2}$, Alexandra McDonald ${ }^{1}$, Janet Stocks ${ }^{3}$, Paul Aurora ${ }^{3,4}$, Ammani Prasad ${ }^{4}$, Tim J. Cole ${ }^{3}$ and Gwyneth Davies ${ }^{3,4}$

${ }^{1}$ Hospital for Sick Children, Toronto, ON, Canada. ${ }^{2}$ Royal Brompton Hospital, London, UK. ${ }^{3}$ UCL Institute of Child Health, London, UK. ${ }^{4}$ Great Ormond Street Hospital for Children NHS Trust, London, UK.

Correspondence: Sanja Stanojevic, Division of Respiratory Medicine, Hospital for Sick Children, 555 University Ave, Toronto, Ontario, M5G 1X8, Canada. E-mail: Sanja.Stanojevic@sickkids.ca

Received: Oct 082014 | Accepted after revision: Jan 30 2015 | First published online: April 022015

Support statement: This study was supported by the UK Cystic Fibrosis Trust (grant VIA 004) and the UK Medical Research Council (grant MR/J004839/1). Funding information for this article has been deposited with FundRef.

Conflict of interest: None declared.

\title{
References
}

Cystic Fibrosis Foundation. Patient Registry: Annual Data Report 2012. Bethesda, Cystic Fibrosis Foundation, 2013. Cystic Fibrosis Trust. Cystic Fibrosis: Our Focus. UK Cystic Fibrosis Registry Annual Data Report 2012. Bromley, Cystic Fibrosis Trust, 2013.

3 The Canadian Cystic Fibrosis Registry. 2012 Annual Report. Toronto, Cystic Fibrosis Canada, 2014

4 Fogarty A, Hubbard R, Britton J. International comparison of median age at death from cystic fibrosis. Chest 2000; 117: $1656-1660$.

5 Merkus PJ, Tiddens HA, de Jongste JC. Annual lung function changes in young patients with chronic lung disease. Eur Respir J 2002; 19: 886-891.

6 Rosenfeld M, Pepe MS, Longton G, et al. Effect of choice of reference equation on analysis of pulmonary function in cystic fibrosis patients. Pediatr Pulmonol 2001; 31: 227-237.

7 Quanjer PH, Stanojevic S, Cole TJ, et al. Multi-ethnic reference values for spirometry for the 3-95-yr age range: the global lung function 2012 equations. Eur Respir J 2012; 40: 1324-1343.

8 Knudson RJ, Lebowitz MD, Holberg CJ, et al. Changes in the normal maximal expiratory flow-volume curve with growth and aging. Am Rev Respir Dis 1983; 127: 725-734.

9 Wang X, Dockery DW, Wypij D, et al. Pulmonary function between 6 and 18 years of age. Pediatr Pulmonol 1993; 15: 75-88.

10 Hankinson JL, Odencrantz JR, Fedan KB. Spirometric reference values from a sample of the general U.S. population. Am J Respir Crit Care Med 1999; 159: 179-187.

11 Kirkby J, Aurora P, Spencer $\mathrm{H}$, et al. Stitching and switching: the impact of discontinuous lung function reference equations. Eur Respir J 2012; 39: 1256-1257.

12 Quanjer PH, Stanojevic S, Stocks J, et al. Changes in the FEV/FVC ratio during childhood and adolescence: an intercontinental study. Eur Respir J 2010; 36: 1391-1399.

13 Miller MR, Pedersen OF. New concepts for expressing forced expiratory volume in $1 \mathrm{~s}$ arising from survival analysis. Eur Respir J 2010; 35: 873-882.

14 Stanojevic S, Wade A, Stocks J. Reference values for lung function: past, present and future. Eur Respir J 2010; 36: $12-19$.

\section{Public awareness on cystic fibrosis: results from a national pragmatic survey}

To the Editor:

Cystic Fibrosis (CF) is a life threatening disorder that primarily affects the lungs and digestive system that represents an important cause of morbidity and mortality. Research has provided effective tools for disease prevention and treatment [1]. Defective gene and its protein product were discovered in 1989 [2-4] and screening systems are available for carrier identification [5] Moreover, new-borns screening for CF facilitates early diagnosis and genetic counselling. Thanks to more effective drugs availability [6, 7], life expectancy has significantly grown in the last decades [8], with more than $45 \%$ of the CF patients aged $>18$ years and with a satisfying quality of life [9]. 
Public awareness on genetic disorders is essential for disease prevention, early diagnosis and treatment. Moreover, it is relevant to sensitise institutions to provide the best possible healthcare, social and environmental facilities for patients, families and care managers.

In order to capture information for CF education and advertising campaigns, the Lega Italiana Fibrosi Cistica - Lombardia (Milan, Italy), endorsed a public pragmatic survey, aimed to evaluate Italian adults' knowledge about CF prevention, diagnosis and treatment.

This ad hoc survey was conducted by DOXA Marketing Advice (Milan, Italy) who recruited volunteers and attended to the methodology and data analysis. A sample of 1006 individuals that represented the Italian population aged $\geqslant 15$ years (52.1 million people) was used.

The need to accommodate a maximum margin of sampling error was taken into account: considering 1006 respondents out of an overall population of more than 52 million, a sampling error of $\pm 2.88 \%$ is reported, which ensures a confidence level of $99 \%$ in the worst-case scenario of parameter estimation $(\mathrm{p}=50 \%)$.

The survey was based on interviews in the respondents' homes. A questionnaire, developed by a panel of experts in the treatment of CF patients, which took approximately $15 \mathrm{~min}$ to complete, with the support of a laptop computer (computer-assisted personal interviewing system) was adopted.

A total of 130 trained interviewers conducted the survey between May 25, 2014 and June 3, 2014. The community under study was divided into sections or "layers" based on two criteria, the region and the size of the municipality of residence.

The number of interviews conducted in each layer was calculated to ensure that the number of interviews was proportional to the distribution among the various layers of communities under study.

All of the units included in the sample constitute a miniature reproduction of the community being considered (proportional stratified sampling method). The names and addresses of the interviewed were extracted from the electoral roll. People aged 15-17 years, who cannot yet register to vote, were selected using the quotas method.

During the processing phase, the data were weighted and a weighting factor was assigned to each interview to perfectly balance the sample compared to the reference population. The following variables were considered: sex according to age, region according to town amplitude, education (degree/diploma/middle school/elementary school), and employment status (working/not working).

A descriptive analysis of the answers was performed, and the Chi-squared test was used to test for associations between answers and membership in a particular group. The relationship between single items and the general opinion regarding inhaler devices (latent importance) was evaluated using the $t$-test.

1006 individuals (52\% females) were evaluated. To assess their awareness of CF, the respondents were asked whether they had recently heard of any of several lung diseases. $64 \%$ of those interviewed claimed that they had previously heard about CF; $47 \%$ of them had been informed from watching the television, $13 \%$ from

TABLE 1 Subgroup analysis of the 1006 respondents

\begin{tabular}{|c|c|c|c|c|c|c|c|c|c|c|}
\hline Awareness of & $\begin{array}{l}\text { Answered } \\
\text { the question }\end{array}$ & \multicolumn{9}{|c|}{ Respondents } \\
\hline CF disease features & 64 & 65 & 73 & 55 & 60 & 68 & 69 & 63 & $40^{\pi}$ & 18 \\
\hline CF heritability & 20 & $13^{+}$ & 28 & $10^{\S}$ & 17 & 22 & 30 & 17 & & \\
\hline Diagnostic test ${ }^{\#}$ & 16 & 14 & 21 & 8 & 15 & 17 & 26 & 14 & $21^{\pi}$ & 8 \\
\hline Neonatal screening & 47 & $47^{f}$ & 55 & $32^{\# \#}$ & 45 & 50 & $64^{917}$ & 44 & 56 & 32 \\
\hline Carrier prevalence & 8 & 7 & 10 & 5 & 9 & 7 & 9 & 8 & $10^{++}$ & 4 \\
\hline Test for carrier detection & 29 & 22 & 33 & 27 & 28 & 30 & 40 & 265 & $39 \pi$ & 11 \\
\hline Oxygen therapy & 37 & 28 & 41 & 39 & 36 & 38 & 42 & 36 & $48^{\pi}$ & 18 \\
\hline Mechanical ventilation & 34 & 24 & 39 & 35 & 33 & 35 & 39 & 33 & $44^{\pi}$ & 15 \\
\hline
\end{tabular}

Data are presented as percentages. " : sweat and genetic tests; ${ }^{n}: \mathrm{p}=0.0001$ versus claimed not to know about cystic fibrosis (CF); ${ }^{+}: \mathrm{p}=0.0001$ versus $35-64$ years; $^{\S}$ : $p=0.0233$ versus adult; ${ }^{f}: p=0.0398$ versus aged $\geqslant 65$ years; ${ }^{\# \#}: p=0.0007$ versus $35-64$ years; ${ }^{\text {กी }}$ : $p<0.0001$ versus without son aged $\leqslant 14$ years; ${ }^{++}: p=0.003$ versus claimed not to know about CF. 

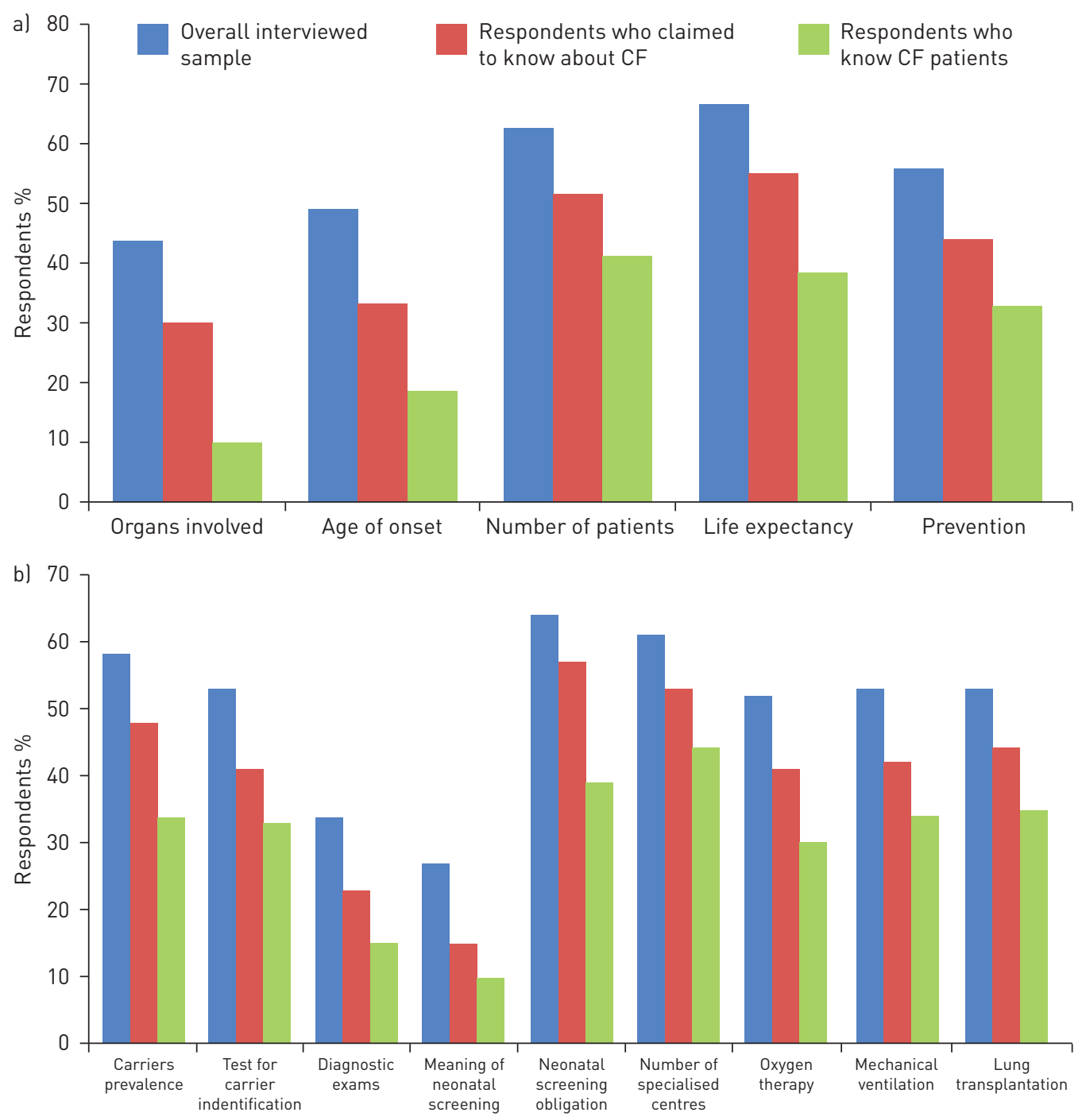

FIGURE 1 Percentage of respondents who provided incorrect answers or were not able to answer the survey questions.

reading newspapers/magazines, $8 \%$ know a CF patient, $3 \%$ from talking to a physician and $2 \%$ from using the web. In addition $20 \%$ of the sample was aware about the disease being hereditary. No difference concerning nominal awareness and disease hereditary were shown in accordance with employment, socio-economical status, the size of the town of residence, ownership of a personal computer and internet use. A high degree of education was associated with a higher knowledge of CF transmission. Only 19\% of those interviewed and who were aware of CF correctly estimated the the number of Italians suffering from CF (5000 patients [10]), with an odds ratio of 4.9 for correct estimation amongst those interviewed who were aware of CF and an odds ratio of 1.8 among those who know CF patients. 53\% of the population aware of CF knew that the lungs and the digestive system were the organs that are most involved in the disease (odds ratio of 4.1 among people who know CF patients). $49 \%$ of those interviewed did not know the age of onset for symptoms for CF, while $67 \%$ were not aware about life expectancy. $56 \%$ did not know if CF is preventable or not, while $20 \%$ consider CF preventable. Only $16 \%$ of the sample considers sweat test and genetic analysis fundamental in the diagnosis of CF, while $39 \%$ and $31 \%$ indicate lung CT scan and a blood test, respectively, are essential in diagnosis. Neonatal screening is considered an efficient diagnostic tool by $47 \%$ of interviewed and only $10 \%$ are aware that, in Italy, this test is mandatory. About two-thirds of the sample is not aware that the carrier status may be discovered using a blood test. Among the persons aware about genetic analysis, $45 \%$ suggests that the test should be performed before pregnancy on all parents, while, surprisingly, $19 \%$ would make the test available for all couples "during" pregnancy. Frequency of carrier status (estimated as 1 in 30 people [11]) has been correctly identified by $8 \%$ of the sample. Respondents were asked if oxygen therapy, mechanical ventilation and lung transplant are used in the end stage of CF; 53\% of were not able to answer to the questions while $37 \%, 34 \%$ and $26 \%$, respectively, were aware of the use of these treatments. The results 
of the statistical analysis on the above mentioned topics according to sex, having or not having a son aged $\leqslant 14$ years, being knowledgeable or not about CF, and of knowing CF patients are reported in table 1 and in figure 1. The vast majority of respondents (77\%) believed that CF patients must be cared for by highlyspecialised centres although they are not aware about the real existence of these.

The awareness of CF is still poor. In particular, knowledge about the pattern of inheritance seems to be lacking as well as age of onset and life expectancy. Respondents aged 35-64 years were more aware about the heritability of $\mathrm{CF}$ and the availability of neonatal screening when compared with either the older or younger population surveyed. No significant difference was found between sex, while respondents with sons aged $\leqslant 14$ years were more aware of neonatal screening than those without sons. Respondents who claimed to know of CF were significantly more aware, than those who do not know of CF, concerning disease features, diagnostic tests, carrier prevalence and detectability, utility of oxygen therapy, mechanical ventilation and lung transplantation. Based on this finding we recommend more educational campaigns targeting all populations with particular attention to those aged $\leqslant 34$ years and males. Informational programmes should educate the public through television broadcasts, life lectures and seminars, emphasising the nature of inheritance, the available preventive measures, the differences between carriers and affected individuals. In Italy, a minority of couples discuss their reproductive plans with a health professional, usually a gynaecologist, before the pregnancy, an attitude which is possibly driven by the fact that this service is reimbursed by the health system in some areas. More resources should be devoted to pre-conceptional counselling, which may explore and illustrate reproductive options and risks and inform about neonatal screening aims and management.

@ERSpublications

The results of a national pragmatic survey show that public awareness on cystic fibrosis is poor http://ow.ly/JztjM

Fulvio Braido ${ }^{1,5}$, Ilaria Baiardini ${ }^{1,5}$, Massimo Sumberesi ${ }^{2}$, Giorgio Walter Canonica ${ }^{1}$, Francesco Blasi ${ }^{3}$ and Carlo Castellani ${ }^{4}$

${ }^{1}$ Allergy and Respiratory Diseases Clinic, DIMI, University of Genoa, IRCCS AOU San Martino-IST, Genoa, Italy. ${ }^{2}$ DOXA Marketing Advice, Milan, Italy. ${ }^{3}$ Dept of Pathophysiology and Transplantation, Università degli Studi di Milano, IRCCS Fondazione Ca' Granda, Ospedale Maggiore Policlinico, Milan, Italy. ${ }^{4}$ Cystic Fibrosis Center, Azienda Ospedaliera Universitaria Integrata, Verona, Italy. ${ }^{5}$ Both authors contributed equally.

Correspondence: Fulvio Braido, Allergy and Respiratory Diseases Clinic, DIMI, L.go R. Benzi, 10-16132, Genoa, Italy. E-mail: fulvio.braido@unige.it

Received: Dec 012014 | Accepted after revision: Jan 312015 | First published online: April 162015

Support statement: The survey was conducted with an unrestricted educational grant for observational research and communication on Cystic fibrosis Awareness provided to NET Congress \& Education CME Provider by the Italian Society of Respiratory Medicine (S.I.Me.R.) Forest Laboratories Italy Srl, and Novartis Farma Spa, Vertex Pharmaceuticals Italy Srl.

Conflict of interest: Disclosures can be found alongside the online version of this article at erj.ersjournals.com

Acknowledgements: The authors thank Lega Italiana Fibrosi Cistica - Lombardia (Milan, Italy).

\section{References}

$1 \quad$ Voter KZ, Ren CL. Diagnosis of cystic fibrosis. Clin Rev Allergy Immunol 2008; 35: 100-106.

2 Riordan JR, Rommens JM, Kerem B, et al. Identification of the cystic fibrosis gene: cloning and characterization of complementary DNA. Science 1989; 245: 1066-1073.

3 Rommens JM, Iannuzzi MC, Kerem B, et al. Identification of the cystic fibrosis gene: chromosome walking and jumping. Science 1989; 245: 1059-1065.

4 Kerem B, Rommens JM, Buchanan JA, et al. Identification of the cystic fibrosis gene: genetic analysis. Science 1989; 245: 1073-1080.

5 Langfelder-Schwind E, Karczeski B, Strecker MN, et al. Molecular testing for cystic fibrosis carrier status practice guidelines: recommendations of the National Society of Genetic Counselors. J Genet Couns 2014; 23: 5-15.

6 Sears EH, Gartman EJ, Casserly BP. Treatment options for cystic fibrosis: state of the art and future perspectives. Rev Recent Clin Trials 2011; 6: 94-107.

7 Davies JC, Ebdon AM, Orchard C. Recent advances in the management of cystic fibrosis. Arch Dis Child 2014; 99: 1033-1036.

8 Hoo ZH, Wildman MJ, Teare MD. Exploration of the impact of 'mild phenotypes' on median age at death in the UK CF registry. Respir Med 2014; 108: 716-721.

9 Tuchman LK, Schwartz LA, Sawicki GS, et al. Cystic fibrosis and transition to adult medical care. Pediatrics 2010; 125: 566-573.

10 Burgel PR, Bellis G, Olesen HV, et al. Future trends in cystic fibrosis demography in 34 European countries. Eur Respir J 2015; 46: 133-141.

11 Castellani C, Picci L, Tamanini A, et al. Association between carrier screening and incidence of cystic fibrosis. JAMA 2009; 302: 2573-2579. 